IZA DP No. 4229

Fat and Out in Salerno and Province: Adolescent Obesity and Early School Leaving in Southern Italy

Adriana Barone

Niall O’Higgins

June 2009 


\title{
Fat and Out in Salerno and Province: Adolescent Obesity and Early School Leaving in Southern Italy
}

\author{
Adriana Barone \\ CELPE and DiSES, University of Salerno \\ Niall O'Higgins \\ CELPE and DiSES, University of Salerno \\ and IZA
}

Discussion Paper No. 4229

June 2009

IZA

P.O. Box 7240

53072 Bonn

Germany

Phone: +49-228-3894-0

Fax: +49-228-3894-180

E-mail: iza@iza.org

\begin{abstract}
Any opinions expressed here are those of the author(s) and not those of IZA. Research published in this series may include views on policy, but the institute itself takes no institutional policy positions.

The Institute for the Study of Labor (IZA) in Bonn is a local and virtual international research center and a place of communication between science, politics and business. IZA is an independent nonprofit organization supported by Deutsche Post Foundation. The center is associated with the University of Bonn and offers a stimulating research environment through its international network, workshops and conferences, data service, project support, research visits and doctoral program. IZA engages in (i) original and internationally competitive research in all fields of labor economics, (ii) development of policy concepts, and (iii) dissemination of research results and concepts to the interested public.
\end{abstract}

IZA Discussion Papers often represent preliminary work and are circulated to encourage discussion. Citation of such a paper should account for its provisional character. A revised version may be available directly from the author. 


\begin{abstract}
Fat and Out in Salerno and Province: Adolescent Obesity and Early School Leaving in Southern Italy*

In this paper, we focus on the causes and consequences of adolescent obesity from an economic perspective. The paper examines the determinants of obesity and its role in influencing early school leaving amongst adolescents in the province of Salerno in Southern Italy. A simple human capital investment model is employed and this provides a framework within which to analyse the interrelated 'decisions' regarding schooling and overeating, taking into account the importance of time preference and the differential effects of adolescent obesity for males and females. We find that: a) there is a strong and robust positive effect of obesity on early school leaving; b) there are significant gender differences in the nature of this relationship; and, c) although not statistically significant, there is support for the idea that contextual factors - such as the type of school attended - are important in determining the effects of obesity on early school leaving. These findings have important policy implications. In particular, evidence on the positive causal link running from obesity to early school leaving suggests: i) that action aimed at reducing obesity - such as the encouragement of sporting activity - may also have beneficial effects in terms of reducing early school leaving rates; ii) the introduction of financial incentives to encourage educational participation; and, iii) the significant differences identified between young men and young women suggest the adoption of some gender- specific policy measures.
\end{abstract}

JEL Classification: I12, I21, J13

Keywords: obesity, early school-leaving

Corresponding author:

Niall O'Higgins

DiSES

Università di Salerno

Via Ponte Don Melillo

84084 Fisciano (SA)

Italy

E-mail: nohiggins@unisa.it 


\section{Introduction}

Over the last decade or so, both the general public and academics have increasingly focused their attention on the causes and consequences of obesity. Initially, the issue was mainly examined in the medical literature, but more recently theoretical and empirical analyses of obesity from an economic point of view have begun to emerge ${ }^{1}$.

In this paper, we use data from a unique survey of school students in the Province of Salerno in Southern Italy to analyse the causes and consequences of adolescent obesity from an economic perspective. There are numerous analyses of the negative effects of obesity on earnings, several of which are discussed further in the next section. One possible long-term channel for this negative impact to operate is through the effect of obesity on scholastic performance. In the USA, for example, Crosnoe (2007) has found a negative relation between adolescent obesity and subsequent college enrolment for young women and Sabia (2007) finds a robust and significant relationship between BMI and the academic performance for adolescent (14-17 year old) white females. These results are discussed further below. The analysis presented here belongs to this line of research, specifically, looking at the effect of adolescent obesity - along with other factors such as family background, previous educational attainment, lifestyle and local context - on early school leaving and thus, by implication, on the long-term earnings potential of individuals. Overweight children and adolescents run a greater risk of becoming obese adults with all the negative labour market (and other) consequences that this implies but obesity is also likely to affect them more immediately through its impact on schooling.

Although the association between obesity and lack of educational attainment is observable in the medical literature (for example, Mokdad et al. (2001, table 1, p. 1196) for data on the USA), relatively few papers have thusfar explicitly analysed this aspect in any detail. Indeed, this paper is the first to look at the role of effects of obesity on early school leaving in Italy where the obesity and early school leaving rates are both notably higher in the relatively poor Southern part of the country. We develop a simple human capital investment framework which allows us to interpret the effects of various factors, including obesity, on school-leaving. Amongst other things, such a framework explicitly models the key role of the future consequences of current actions - through the relative weight attributed to the future by the individual.

In part, the analysis draws on the health-related literature which has long noted the positive association between health and schooling. Grossman (2000) has identified three basic mechanisms

\footnotetext{
${ }^{1}$ See, for example, Finkelstein at al. (2005), Suhrcke et al. (2005), Rosin (2008) for general analyses of the issues in addition to the discussion below.
} 
through which health and schooling maybe related. First, more schooling may improve health. Second, better health may facilitate study. Third, other factors, such as physical activity, time preference and parental characteristics, may well influence both health and studying. The analysis undertaken here is centred around the second of these - the effect of obesity on schooling - but the analysis also incorporates consideration of the first and third of these mechanisms.

The analysis produces some interesting results. In particular, we find that: a) there is a strong and robust positive effect of obesity on early school leaving; b) there are significant gender differences in the nature of this relationship; and, c) although not statistically significant, there is support for the idea that contextual factors - such as the type of school attended - are important in determining the extent to which obesity affects early school leaving.

The following section provides an overview of trends in Europe in general and in Italy in particular. Section three briefly reviews the literature on the economic causes and consequences of obesity focusing on the phenomenon of increasing adolescent obesity. Section four outlines a human capital investment model in order to aid interpretation of results and section five discusses the data and variables used in the analysis, whilst section six presents the basic empirical models and the results of estimating them. The final section offers some concluding comments.

\section{Some Stylised Facts on Obesity}

Several recent studies have looked at trends over time in child and adolescent obesity. Lobstein et al. (2004) and Wang and Lobstein (2006) have provided an overview of worldwide trends from the 1970s to the end of the 1990s. These studies note that the phenomenon is increasing in almost all industrialized countries and in several lower income countries and is affected by socioeconomic status (SES) although the extent of the influence depends upon the aggregate economic context. In middle income countries, members of better off households are more likely to be at risk of overweight compared with members of poorer households. As economies develop, higher obesity levels are found among lower income groups. In industrialized, economically developed countries, children in the lowest SES groups may be at greatest risk of overweight. Obesity is still infrequent in rural parts of many lower income countries and also tends to fall when economic development suffers a reversal as happened in the countries of Central and Eastern Europe following transition. With recovery, however, obesity in the population increased in several of these countries such as Eastern Germany and Croatia. The higher prevalence of obesity in lower socioeconomic groups in Europe is confirmed also by the analysis of Sanz de Galdeano (2005) and in the USA by Baum and Ruhm (2007). 
According to the International Obesity Task Force (IOTF, 2005, p. 4), in Europe the problem is particularly acute in the Mediterranean with Italy, Malta, Portugal and Spain (as well as the islands of Gibraltar and Crete) facing a prevalence of overweight and obesity of over $30 \%$ amongst 7-11 year old children. Amongst the adolescent group of 13-17 year olds, Italy is only superseded by Crete and England in terms of overweight and obesity, although for obesity in isolation it fares slightly better, being lower than in Ireland, Greece and Spain in addition to Crete and England. In their study of overweight and obesity amongst young Italians (aged 6-17), based on data from the National Statistical Institute ${ }^{2}$, Gargiulo et al. (2004) have highlighted the much greater prevalence of obesity in the poorer regions of the South albeit with strong regional variations. A similar pattern is also observable in early school leaving, with the prevalence being higher in Southern Italy. Table 1 illustrates the association between these phenomena observable at the Macro-regional level. Indeed, one of the motivating forces underlying our analysis is the desire to better understand the relation between these two phenomena.

\section{(Table 1 about here)}

\section{The Causes and Consequences of Obesity}

The European Commission (Suhrcke et al., 2005) has recently stressed the importance of addressing the issue of socioeconomic inequalities as a central element of strategies to combat obesity, emphasising the fact that food choice is determined by both individual preferences and socioeconomic factors. Social position, income and education are all determinants of diet and physical activity. Income may well affect the ability to access recreation facilities and lower levels of education and the consequent poorer access to relevant information may reduce the capacity of individuals to make informed choices. Amendola and Mancini (2005) have found a negative correlation between socioeconomic status and obesity amongst secondary school students (14-19) in Italy. This points to the lower per capita income as one possible explanation of the higher obesity rates observable in Southern Italy. In their aforementioned analysis of Italy, Gargiulo et al. (2004) identify three principal risk-factors associated with child and adolescent (6-17 years old) obesity: a) the existence of obese parents and/or other family members; b) a sedentary lifestyle; and, c) the socioeconomic status (family income and education level of mother).

\footnotetext{
${ }^{2}$ Istat (2002). This is a survey of 17,500 children and adolescents in Italy between 6 and 17 years old.
} 
The World Health Organisation (WHO, 2006a, 2006b) has looked at the socioeconomic determinants of healthy eating habits and physical activity levels amongst young people in Europe. In a survey carried out in five Italian Regions (Lazio, Abruzzo, Molise, Campania and Puglia) during the school year 2002-03, La Torre et al. (2006) found a positive relationship between children's participation in extra-curricular physical activity and their family's Socioeconomic Status. The WHO's Health Behaviour in School aged Children (HBSC) study identifies, in addition to the aforementioned factors, the central importance of another factor: mental health, which includes life satisfaction and body image and which is influenced by the mass-media. In this view, childhood and adolescent nutrition, physical exercise and mental health are all influenced by socioeconomic and environmental factors as well as by models of appearance and behaviour aggressively promoted through the media.

Of course, the direction of causation may also be inverted - for example, lower socioeconomic status may also be a consequence of obesity as well as its cause. Indeed, there is a fairly well developed literature, discussed further below, which looks at the economic consequences of obesity in terms of the lower earning potential and occupational attainment of overweight adults. More generally several studies have looked at the shorter and longer term health consequences of obesity: the direct health risks associated with child and adolescent excess body weight; and the longer term health consequences of adult obesity given the strong relation between obesity in childhood and adulthood (Lobstein et al. 2004). Thus, for example, Lake et al. (1997) look explicitly at the dual relationship between: a) obesity in parents and their children; and, b) the correlation between obesity in childhood and adulthood. Not only do they find a strong correlation between obesity in childhood and adulthood, they also find that this correlation is significantly greater when the child under consideration is born of obese parents. Moreover, the various causative factors underlying obesity may also interact. Thus, various surveys conducted in high income countries show that both adults and children from disadvantaged socioeconomic backgrounds tend to be more sedentary than those boasting more privileged circumstances, potentially due to the lower availability and affordability of facilities and activities, less leisure time, and poorer knowledge and fewer positive attitudes about the benefits of exercise (Sarlio-Lähteenkorva and Lahelama, 1999). Moreover, the WHO (2006a, 2006b) note that obesity also reduces the number of social relationships among adolescents and their perceived popularity amongst peers and increases time off school leading to lower educational and occupational attainment which may in turn further reinforce the relationship between lower socioeconomic status and obesity.

In general, reductions in the strenuousness of jobs (Philipson, 2001, Lakdawalla and Philipson, 2002 and Lakdawalla et al., 2005), technological innovation in food processing and 
preparation (Cutler and al., 2003), the growing availability of restaurants (Chou et al., 2004, Rashad et al., 2005), increasing urban sprawl (Ewing at al., 2003), greater discounting of the future (Fuchs, 1982, 2004, Komlos et al., 2004, Smith et al., 2005, Borghans and Golsteyn, 2006, Zhang and Rashad, 2008), time inconsistent preferences (O'Donoghue and Rabin, 1999, 2000, Cutler et al., 2003), having health insurance (Rashad and Markowitz, 2007), higher unemployment (Ruhm, 2000) and maternal employment ${ }^{3}$ (Anderson and al., 2003, Cawley and Liu, 2007) have all been found to have a positive impact on obesity.

As to the economic consequences of obesity, there is a fairly well developed literature analyzing the lower earning potential of overweight adults in the labour market. One consistent result in this literature is that the income penalty associated with obesity is greater for women than for men; more often than not, there appears to be no corresponding penalty for men. Register and Williams (1990) find a statistically significant wage penalty (of 12\%) for obese young American women (compared to non-obese women) but no statistically significant penalty for obese men. Harper (2000) obtains a similar result for British women. Averett and Korenman (1996) find statistically significant negative effects of obesity early in life on income later on for both men and women, although the effect is much lower for the former. Moreover, taking the analysis a little further (and using an IV approach to control for the endogeneity of the BMI), Pagan and Davila (1997) again find a statistically significant wage penalty for women but not for men ${ }^{4}$, explaining this in terms of the fact that obese women tend to work in relatively low-paid occupations and are largely excluded from higher income managerial, professional and technical occupations. Morris (2006) analyses gender differences in the effects of obesity on occupational attainment. Here too, the findings confirm a more detrimental effect of obesity on women than on men. Brunello and D’Hombres (2007) find similar differential effects for women and men in a range of European countries, with the effect being more pronounced in Southern European countries than in the Northern part of the continent. Cawley $(2000,2004)$ finds that the female weight penalty applies principally to white women (as opposed to black or Hispanic women or indeed, white, black or Hispanic men) explaining this in terms of a larger negative self esteem effect of greater weight for that 'ethnic group'. Tosini (2008) finds that a substantial part of the observed negative relation between female obesity and wages can be accounted for by unobserved permanent characteristics. That is, that the type of women who are likely to become obese tend to receive wage (and spousal income) offers which are much lower than those received by women who do not share this tendency. Lempert (2007) has further found that the weight penalty for white women has increased

\footnotetext{
${ }^{3}$ Cawley and Liu suggest that maternal employment has an effect on the mother's allocation of time to activities related to their children's diet and physical activity increasing the risk of childhood obesity.

${ }^{4}$ Indeed, Pagan and Davila (1997) actually find an albeit small net positive effect of obesity on wages for men.
} 
over time notwithstanding the fairly rapid growth in average weight in the US over the last two decades. Conley and Glauber (2005) find that the negative effects of obesity extend to a wide range of economic outcomes for women, but again not for men.

In any event: i) numerous studies have found a negative wage penalty associated with obesity; and, ii) usually, this penalty is found to be larger for women than men. One channel through which these effects may arise is through a negative impact of obesity on human capital accumulation. In this regard, Sargent and Blanchflower (1994) find that adolescent obesity at age 16 in Britain was associated with lower educational attainment for both young men and young women and with lower earnings at age 23 for young women. Taras and Potts-Datema (2005) have reviewed nine papers examining the link between obesity among school-aged children and school performance, demonstrating that overweight and obesity are associated with poorer levels of academic achievement. Moreover, Karnehed et al. (2006) find that young obese men have a much lower chance of completing three years of tertiary education than normal-weight individuals even after adjustment for intelligence and socioeconomic position. According to the authors, a possible explanation for this result is discrimination in the educational system and other sectors of the society.

Sabia (2007), building on the work of Cawley (2004), has analyzed the relationship between adolescent body weight and academic performance. The results obtained suggest robust evidence of the existence of a negative relationship between body weight and academic attainment amongst white females, but not among males and non-white women. The author suggests that this negative effect might have three possible explanations:

a) differences in human capital accumulation;

b) a common unobserved factor, such as self-esteem, which is influenced by body weight and influences both academic attainment and wages; and/or,

c) discrimination against obese white females at school and market-level.

Cawley and Spiess (2008) have investigated the association between obesity and skill attainment in early childhood (aged 2-3 years). They found that, already at this age, obesity is associated with lower skill attainment, but in this case the association is stronger for boys than girls. These two findings are also in line with the results reported by Datar et al.(2004) looking at the association between test scores and obesity in children attending kindergarten and first grade. On the other hand, Wendt and Kinsey (2009) find a relation between obesity and academic achievement for children at elementary school (between ages 5 and 12). In common with the studies 
of adolescents and young adults, they find a stronger relation for females. Finally, Kaestner and Grossman have also looked at this relation in US children (5-12) however, finding no such relation.

Thus, the vast bulk of the studies looking at the issue have found a negative relation between obesity and academic performance. In very young children, this negative association is stronger for boys than girls, whereas the studies looking at this relation in amongst slightly older children and amongst adolescents and young adults have found the relation to be stronger for young women than young men. Cawley and Spiess (2008), suggest that discrimination is not sufficient to explain the negative relation and, moreover that explaining the reasons for such gender differences in adulthood is an important area for future research. Here, we attempt to make a contribution to this line of research, in particular focussing on the association between obesity and dropping out of school differentiating between males and females.

The next section offers a simple human capital investment model in which current behavioural choices has an impact on future outcomes and where the individual rate of time preference has an important role in influencing current decisions. Thus, this model suggests one possible mechanism through which obesity may affect adolescent human capital accumulation.

\section{Analytical framework}

As suggested above, a simple human capital investment model is employed here to help guide the analysis and interpretation of the results reported subsequently. Clearly, such a model is an oversimplification but does aid in clarifying some of the issues involved. We are concerned here with the relationship between alimentary and school outcomes. The model proposed makes explicit the notion that current behavioural 'choices' may have longer term consequences and thus relates behaviour at in one period to effects later on in life, thus emphasising the role played by time preference. As is well known, the individual rate of time preference, $r$, plays an important role in human capital investment decisions (Becker, 1964). This has been confirmed by empirical analyses such as that of Fersterer and Winter-Ebmer (2003) who find, as one would expect, a negative relationship between the rate of time preference and the duration of educational participation amongst young people. However, it has been suggested that healthy behaviour may also be thought of as an investment in human capital (Grossman 1972) thus differences in time preference may also explain variations in health outcomes even though, from the empirical point of view, the relation between time preference and healthy behaviour is not very robust (Fuchs 1982). Moreover, study and healthy behaviour may well be complementary. The basic idea is captured by the old Latin 
proverb "mens sana in corpore sano". From this viewpoint, the ideal strategy for an adolescent is to mix both types of activity because study and sport complement each other. Such a strategy may raise the probability of finding a better job because better health due to sport activities could lead one to invest more in education. Several studies have found evidence that the effect of sport on educational attainment and labour market outcomes is statistically significant and positive (Long and Caudill, 1991, Barron and al., 2000 and Pfeifer and Cornelißen, 2007, particularly for the first effect).

The model incorporates three central elements:

a) the importance of current decisions on future income;

b) the consequent central role played by time preference; and,

c) the direct relation between obesity and schooling outcomes.

In the current context, we employ a simple 2 period (lets say adolescence and adulthood) human capital model in which adolescents:

a) are either obese $(\mathrm{E}=1)$ or not $(\mathrm{E}=0)$ according to their past behaviour and characteristics; and,

b) decide whether to drop out of school $(S=0)$ or not $(S=1)$.

As regards point a), weight gain, and consequently obesity, depend on an individual's calorific intake (C) as well as her physical activity (A), mediated by a person's physical constitution. Specifically, one may think in terms of an unobserved variable, $\mathrm{E}^{*}$, representing a person's tendency to gain weight:

$$
E^{*}=\phi C-\gamma A
$$

This formulation is closely related to the concept of energy balance (specifically $\mathrm{E}=\mathrm{C}-\mathrm{A}$ ) used by, for example, Rashad (2006). The slight difference here arises because we wish to emphasise the role of physical and therefore genetic differences in the tendency to gain weight. In any event, we observe whether adolescents are obese $(E=1)$ or not $(E=0)$, and this occurs iff $E^{*}>0$. Thus, obesity is determined by factors affecting $\mathrm{C}$ and $\mathrm{A}$, but also variables related to adolescents' physical constitution which determine the values of $\phi$ and $\gamma$.

As regards point $b$ ), the decision to stay on at school or leave early depends on the costs and benefits of the two options, and specifically, we hypothesise that, in line with the previous empirical literature discussed above, the net gains from staying on at school will be lower for the obese. 
More formally, during adolescence, individuals decide whether to remain in school or not. They will remain in school if the net present value of the benefits of doing so exceed the costs. The net present value of the two options are as follows:

$$
\begin{cases}W_{u}+\delta W_{u} & \text { if } S=0 \\ -T_{s}+\delta W_{s} & \text { if } S=1\end{cases}
$$

That is, if the person leaves school they earn the unskilled wage, $\mathrm{W}_{\mathrm{u}}$ in both periods (discounted in the second by $\delta=1 /(1+\mathrm{r})$; if they remain in school they earn nothing in the first period and indeed pay costs to do so - including consumption costs, $\mathrm{T}_{\mathrm{s}}$, which might conceivably be negative (i.e. benefits) - whilst in the second period they earned the skilled wage $\mathrm{W}_{\mathrm{s}}$.

Thus an adolescent will remain in school iff:

$$
\delta\left(W_{s}-W_{u}\right) \geq W_{u}+T_{s}
$$

We suppose that the differential between skilled and unskilled wages depends solely on the growth of an individual's human capital consequent on staying on at school, h, so that,

$$
W_{s}=(1+h) W_{u}
$$

with,

$$
\mathrm{h}=\mathrm{ae} \quad \mathrm{a}>0
$$

and

$$
e=\frac{\theta}{1+\mu E} \quad \theta, \mu \geq 0
$$

That is, being obese reduces the returns to education. Underlying this form is the notion that the human capital gain, h, associated with remaining in school depends positively on the combination of the individual's scholastic effort, e, and her 'ability', a. If the person is obese $(\mathrm{E}=1)$, the efficiency of her scholastic effort will be reduced according to the size of the individual specific parameter $\mu$. That is, obesity may interfere with scholastic effort and consequently reduce the returns to education. This is consistent with the findings reported above of a negative impact of obesity on test scores in early childhood reported above as well as with any of the three mechanisms 
suggested by Sabia (2007) and noted above to explain the negative relation between BMI and academic performance. The formulation may be thought of as a simplified version of the education production function suggested by Hanushek (1986) although the focus there is on school quality rather than individual effort and ability. "Ability" as used here may include other factors, such as family connections or income, indeed any of the many factors which affect an individual's earnings power but which don't depend on (but are of course complementary to) the individual's effort. This could also include school quality à la Hanushek.

Putting these elements together an adolescent will remain in school iff:

$$
\delta a \theta W_{u}-T_{s}-W_{u}-\mu E\left(T_{s}+W_{u}\right) \geq 0
$$

In this formulation, obesity will have a positive impact on the probability of leaving school working through the interaction with the costs of remaining in school ${ }^{5}$. The model is very simple, however, it serves to emphasise several aspects of the school leaving decision on which we wish to focus in the empirical section: in particular, the role of time preference, the role of obesity in increasing the probability of early school leaving as well as the interaction between obesity and other factors in affecting that decision.

One potentially important issue, considered in more detail in section 6 below, is the possible endogeneity of obesity with respect to the early school leaving decision. If adolescents choose E, then in the model outlined above, they will always be thin since there are only costs and no benefits associated with obesity. However, we think it reasonable to start from the proposition that $\mathrm{E}$ is not endogenous: an adolescent becomes obese over an extended period of time - it does not happen instantaneously - largely as a result of genetic factors and choices made during childhood (Lake et al., 1997 and Lobstein et al., 2004, cited above). Such choices are, by their nature, principally made (or at least determined) by a child's parents and other family members ${ }^{6}$. Thus, we expect that obesity will be exogenous with regard to early school leaving simply because adolescents choose

\footnotetext{
${ }^{5}$ Although note that, if say tuition costs have an element which is constant across all individuals in the sample (say $\left.T_{s}=\bar{t}+t_{i}\right)$ the empirical implementation will identify a 'direct' effect of obesity $(\mu \bar{t})$ and one working through the interaction with the variable direct and opportunity costs of education $\left(\mu\left(t_{i}+W_{u}\right)\right)$. Clearly, this is not the only way to formulate the impact of obesity on early school leaving. Obesity might also affect the school leaving decision by increasing the (psychological) costs of education, through, for example, the damaging effects on obese adolescents of teasing and bullying by their classmates.

6. Further support to the "exogenous obesity" hypothesis comes from the medical literature regarding compulsive eating disorders. In regard to both of these considerations - the role of family members and the addictive qualities of (some types of) food - one is reminded of events in England related to the attempts to introduce more healthy school meals there in 2006. In several well-publicised incidents, parents were photographed passing burgers and chips through school fences to satisfy their children's junk(-food) habits. See, for example, The Guardian, 3/10/2006, "The Healthy School Dinners Revolt", http://www.guardian.co.uk/society/2006/oct/03/health.schoolmeals. Of course this does not exclude the joint determination of obesity and early school leaving considered further below.
} 
whether or not to drop out of school but they don't choose whether or not to be obese. Consequently, the empirical analysis initially adopts this assumption, which is then subject to formal testing.

In terms of the empirical counterpart we may think of two latent index functions, $\mathrm{E}^{*}$ and $\mathrm{S}^{*}$ representing unobserved energy balance and schooling effort respectively. These are linear functions of a number of factors which determine energy balance and the costs and benefits of education such that:

$$
\begin{array}{ll}
E^{*}=X_{E} \beta_{E}+\varepsilon_{E} & \varepsilon_{E} \sim N(0,1) \\
S^{*}=X_{S} \beta_{S}+\gamma E+\varepsilon_{S} & \varepsilon_{S} \sim N(0,1)
\end{array}
$$

We observe whether young people are obese $(E=1)$ which occurs iff $E^{*}>0$, or not $(E=0)$; and, whether they leave school early $(S=0)$ which occurs iff $S^{*}<0$, or not $(S=1)$. Unobserved factors affecting obesity and early school leaving, $\varepsilon_{\mathrm{E}}$ and $\varepsilon_{\mathrm{S}}$, are assumed to be randomly distributed with zero mean and are normalised to have unit variance. Such a framework leads naturally to estimation of probit models of obesity and school dropout.

So that equations (7) and (8) form the basis of the first part of section 6 below. Estimation of (7) enables us to test whether contextual factors are indeed associated with the risk of obesity. Estimation of (8) allows us to test the basic hypothesis that obesity increases the likelihood of leaving school. We also employ a formulation which allows interaction between obesity and other factors specifically affecting the direct and opportunity costs of studying. The assumption that obesity is exogenous to early school leaving is of course testable. Given that endogeneity tests in this context require the explicit formulation of instruments for obesity and, in practice, may be sensitive to the specific instruments chosen, we apply different formulations of two types of endogeneity test for the probit model suggested by Smith and Blundell (1986) and Monfardini and Radice (2008) respectively.

\section{Data and variables}

Data for this analysis is drawn from a stratified survey of school age adolescents in the province of Salerno carried out in 2004 by CELPE (Centro Interdipartimentale di Economia del 
Lavoro e di Politica Economica, University of Salerno) on behalf of the Province of Salerno, and supplemented in 2005. The main purpose of the survey was to investigate the phenomenon of early school leaving amongst adolescents (aged 14-17) in the province. The survey collected a wide range of information from young people, including information on family background as well as on a number of health issues which were used to derive the dependent and most of the explanatory variables used here.

The sample was constructed on the basis of information, provided by the local CSA (Centro per i Servizi Amministrativi - the local educational administration), on the distribution of enrollment in the high secondary public school in the Province during the schooling year 20032004. As regards students regularly attending school, a two stage procedure was employed in which 21 of the total of 85 schools in the province were first extracted taking into account the distribution of schools across geographical areas and school type. Secondly around 600 students were randomly drawn from the 21 schools' records. As far as early school leavers in our sample are concerned, a list of names of persons identified as "dropouts" by schools was provided by the local CSA and contained information on around 900 individuals born between 1987 and 1989 inclusive. From these, 178 individuals were interviewed in June/July 2004. In early 2005, a refreshment sample of early school leavers was added through renewed requests for lists of such individuals from all the schools and further attempts were made to contact the members of this enlarged group of early school leavers (1326 as opposed to 900) including also those born in 1990.

Thus, the empirical sampling base consisted of a sample of students along with the entire population of early school leavers identified by the CSA. In other words, relatively speaking, early school leavers are deliberately overrepresented in the sample. This was necessary in order to ensure a group of early school leavers sufficiently large to compare with students ${ }^{7}$. However, of this group of 1326 'officially identified' early school leavers, one-fifth (or 274) were excluded because at the time of the interview, they were discovered to not have interrupted their education (i.e. they were misclassified) and around one-half (or 672) because the contact details given by the CSA were incorrect or because there was no reply to three telephone contact attempts. This left a group of 380 early school leavers, 51 (or 13.4\%) of whom explicitly refused to be interviewed.

To summarize, the final full sample consisted of 918 individuals responding to the questionnaire, however, 123 of these subsequently returned to school and are excluded from the analysis here ${ }^{8}$, leaving a sample of 799 young people: 593 students and 206 permanent school

\footnotetext{
${ }^{7}$ On the basis of the data provided by the CSA, "dropouts" comprised around $2.7 \%$ of the registered school student population in Salerno Province.

${ }^{8}$ O'Higgins et al. (2007) uses the full sample in order to identify the factors which determine the return to school of those who initially dropout.
} 
leavers. This group of young people responded to a questionnaire through direct interview.

As regards the definition of obesity, this was calculated on the basis of the information contained in the survey on young people's (self-reported) height and weight from which it was possible to calculate their BMI (Body Mass Index) ${ }^{9}$ - the standard indicator used to identify overweight and obese individuals. The problem of the accuracy of self-reported weight and height. In general, one would expect the BMI to be somewhat underreported, both because of the tendency to overestimate height as well as to under-report weight. The issue has been reviewed by Lissau et al. (2004, p. 32) who cite several studies which suggest that self-reported weight by adolescents is relatively consistent and, where the correlation has been explicitly measured, they find this to be of the order of between 0.8 and 0.9. As far as the analysis here is concerned, it is important not so much that BMI is underestimated (and consequently that some obese adolescents are misclassified as not obese), but that this misclassification is not systematically related to other factors (observed and unobserved) which determine early school leaving ${ }^{10}$. Danubio et al. (2008) provide support for this proposition. Specifically, they find that the only characteristic systematically related to BMI underreporting amongst Italian University students is gender. Indeed, this is one major reason - in addition to considerations related to more general gender differences in behaviour - to distinguish between the estimates for young men and young women. The possible implication of underreporting is that the effect of obesity on early school leaving may be underestimated. However, given that one finds a statistically significant relationship between obesity and early school leaving, if the under-reporting is not systematically related to other factors which - explicitly or implicitly affect school leaving then such a relationship cannot be due to a spurious correlation arising from mis-reported height or weight. This proposition is further reinforced by the work of Jansen et al. (2006) who find a negative relation between under-reporting and level of education amongst Dutch pre-adolescents (12-13 years old). If true more generally of adolescents, this would suggest that early school-leavers would be more likely to under-report BMI and so the measured relation between obesity (based on self-reported BMI) and early school leaving would, if anything, be negatively biased. It should also be observed that, in line with the recent literature on the measurement of child and adolescent obesity, the critical threshold value of the BMI was set at 28,

\footnotetext{
${ }^{9}$ In practice although this is the standard measure of obesity used ubiquitously throughout the medical, sociological and economic literature, it is not without its critics. For a discussion of the issues, see, for example, Burkhauser and Cawley (2008). From a theoretical point of view, an interesting recent paper by Burke and Frank (2006) has included the definition of obesity itself as an endogenously determined social norm which in itself has implications for the empirical model discussed below.

${ }^{10}$ One might think of self-reported BMI as an instrument for 'real' BMI. As long as the correlation between selfreported BMI and school leaving arises only as a result of the correlation between self-reported and realised BMI, the obesity dummy based on self-reports is a valid instrument for 'real' obesity. .
} 
rather than 30 as is the case for adults ${ }^{11}$.

A number of explanatory variables were also employed and may be grouped as follows:

- Family Background - Several variables were included to capture the impact of various aspects of young people's family background on obesity and dropout. Family Permanent Income, was proxied by three variables: a) whether the individual lived in a owner occupied home; b) the size of the immediate family (inversely related to FPI) ${ }^{12}$; and, c) the number of domestic appliances (broadly defined) available in the household. This includes such items as computers, washing machines and so on but also such things as, for example, means of transport. We use this approach due to the extreme unreliability of reported income - here increased by the fact that it would be reported by the children of those actually earning it and the fact that it is permanent not current income that is the main factor of interest. This approach is actually akin to that adopted by the tax authorities to identify tax evaders - the so-called 'redditometro' - a measure of imputed income based on ownership of houses, boats, cars and so on ${ }^{13}$. Parental Employment, where a dummy was included to represent whether both parents were working (given that both parents live in the household). Complete Family Unit, was also represented by a dummy to capture the presence in the home of two parents (either natural or step). Finally, Maternal Education was captured by the inclusion of two dummies according to whether the mother had obtained a lower secondary diploma (including a vocational diploma) or at least a upper secondary education. Also included was a dummy to identify whether or not the individual was First-Born as well as two variables to capture Parental Attention during early childhood - whether the individual was read to often by their parents and/or given help with their homework (in earlier childhood).

- Health Status - a variable was introduced to control for whether the young person stated that they had Permanent Health Problems which would affect their ability to study or work ${ }^{14}$.

- Previous Educational Attainment - Two variables were introduced to control for School Failure as a means of capturing early educational attainment - failing (at least) a year during either lower secondary (middle) or upper secondary school.

- Educational experiences/relationship to the school - several variables were included here: whether the individual played truant often which we suppose reflects the adolescent's

\footnotetext{
${ }^{11}$ See, for example, Cole et al. (2000). Gianicolo (2003) also comes to a similar view analysing Italian data. Note also, with regard to the issue of mis-reporting considered above, this has the effect also of lowering the threshhold of what constitutes obesity.

${ }^{12}$ The inverse relation between family permanent income or wealth and household size is well established in the literature. See, for example, Greenwood (1987) and/or, for example, Brandolini et al. (2004) on Italy..

${ }^{13}$. See, for example, Agenzia delle Entrate, Circolare n. 49/E, 2007.

14 The possible responses were: yes, temporary; yes, permanent; none; or, no reply.
} 
attitude to the school; whether they were enrolled in a Liceo (the more academically oriented educational stream); and whether they went to school by either bus or on foot (as opposed to in private transport).

- Lifestyle variables - whether the adolescent smokes - taken as an indicator of the proxy of the discount rate, $r$, and whether they often undertook the following activities: looking after one's children or siblings; gardening; Sporting activities; going to the cinema; and, reading. A variable was also included capturing the fact that the young person spent NO time with their partner -which we interpret as not having a partner.

- Local context - three variables were included here - the local unemployment rate, a dummy for residents in Salerno and also a dummy indicating residency in a coastal area ${ }^{-}$The local unemployment rate was defined at the level of the local labour market system (SLL) as defined by ISTAT (the Italian National Statistical Agency). Intuitively, this identifies an area (usually smaller than cities, e.g. Salerno but larger than towns in the province, e.g. Eboli or Amalfi) within which the majority of the working population live and work. In the current analysis there were 24 distinct local labour markets ${ }^{15}$. Similarly, residency in a coastal area was identified with respect to the local labour market systems. Thus, for example, some but not all those residing in Salerno were defined as living on the coast by this criterion whereas all those residing in Amalfi were defined as living on the coast. In any event, these are all factors which we suppose may affect the (opportunity and/or direct) costs/benefits of studying.

Table 2 reports descriptive statistics on all the variables used in the analysis. The specific interpretation of the explanatory variables is taken up in the discussion of the results below.

\section{(Table 2 about here)}

\section{Empirical results}

In this section we first look separately at the determinants of obesity, and, the impact of obesity and other factors on early school leaving. Given the preceding discussion each model is estimated separately for male and female adolescents. We use a large number of explanatory variables for both obesity and school leaving equations principally to reduce the risk that the obesity variable is picking up the effect of some other unobserved factor responsible for determining both

\footnotetext{
${ }^{15}$ For further details on the definition of local labour markets, see, for example, ISTAT (1997).
} 
phenomena thus leading to endogeneity problems. Such an approach, however, is itself open to the objection that some of the explanatory variables, above-all in the obesity equation, may well themselves be endogenous (to obesity). Estimation of probit models of obesity and early school leaving using a more parsimonious specification are reported in the appendix. In this case, all variables which might reasonably be the results of adolescents' choices are excluded from the obesity equation, whilst one or two (type of school and school year failure) are included in the school leaving equation since these 'choices' temporally precede the school leaving 'decision'. It will be observed that, apart from significantly reducing goodness of fit, the results - and above all the impact of obesity on school leaving - change very little using this specification. Subsequently, in section 6.3, the issue of endogeneity is treated in more detail and the estimates are subject to formal endogeneity tests.

\subsection{Determinants of Obesity}

Table 3 reports the results of estimating equation (7). Various factors appear to be important in determining obesity in young people in Salerno and these differ somewhat between young men and young women:

a) being actively involved in sports seems to be important for both young men and young women in reducing the probability of obesity, particularly amongst the latter;

b) again for both young men and young women, spending no time with a partner (i.e. being without a partner) seems to be equally important for both sexes in increasing the probability of obesity although one might wonder in this case whether this is endogenous. An interesting paper by Viner and Cole (2005) shows that adult women who were persistently obese in adolescence are less likely to have a current partner while men who are obese in adulthood were more likely to be married and more likely to have a current partner. In this regard, Averett and Korenman (1999) have distinguished the effect of obesity for white and black women in the US finding that, although obese of both races have lower wages, lower income and lower probabilities of marriage, the effects are smaller for black women. They argue that the income differences between obese and non-obese white women arises from marriage market factors rather than labour market ones - obese black women are less disadvantaged in the marriage market that obese white ones.

c) for young women, living on the coast is an important deterrent to becoming obese. This may be because the area is touristic and so physical appearance may be more obviously important 
to adolescents either through its direct impact on earnings and/or through peer pressures, but may also be due to differing diets between the coast and inland areas. The latter interpretation is more in the line with the idea of obesity as being 'pre-determined';

d) for young men having both parents present in the home (i.e. being part of a complete family unit) appears to reduce the likelihood of obesity. This is in line with the findings of, for example, Gable and Lutz (2000) who found that child obesity was more prevalent in single parent households. For young women, the coefficient is also negative but it is not statistically significant.

\section{(Table 3 about here)}

In general, relatively few factors are statistically significant in the determination of obesity. There is nothing here to contradict the notion of obesity as being (largely) pre-determined. There is weak (i.e. not-statistically significant) evidence that obesity is negatively related to family income and education, but more important seems to be having two parents living in the household. The importance of sport, as well as being in line with a priori expectations, does not contradict the notion of obesity as 'exogenous' in that a tendency towards sporting activity will depend in part on genetic factors and as well as on the degree to which the aptitude for sports is developed through parental (choices about children's) activity earlier in life. In this regard, it should be noted that in Italy, in contrast to many countries such as, for example, the UK, there is practically no provision for sport as part of the curricula in schools. Sporting activities are almost entirely extra-curricula activities, usually undertaken through separate institutions - sporting associations and the like. Consequently, it is by no means automatic that young people engage in any significant sporting activity at school.

\subsection{Effects of obesity and other factors early school leaving}

Table 4 reports the results of a univariate probit model of the probability of early school leaving. In line with the theoretical model above, the effect of variables may be interpreted in terms of their influence on either:

a) the returns to education;

b) the discount rate; and, 
c) the interaction between these factors - in the latter regard, two specifications are offered, one with just a dummy for obesity and a second which includes the possibility of interaction between obesity and environment.

\section{(Table 4 about here)}

It will be observed that obesity is a strong determinant of early school leaving. Other important determinants of this choice are in particular:

1) family background - the level of parental income and education both negatively influence the likelihood of leaving school early as does being the first born in the family;

2) Educational attainment and experience - previous academic performance and attitudes to school as well as the type of school attended are all influential determinants of early school leaving.

3) Lifestyle - in line with previous research on the relationship between involvement in sporting activities and educational attainment, one may observe that participating in sport seems to be an important determinant of remaining in school for young women, although it is not statistically significant for young men. On the other hand, smoking is positively correlated with early school leaving for young men but does not have a statistically significant impact on the choice of young women. The effect of reading (books) often is also more important for young men.

4) local context - One would expect the unemployment rate, as an indicator of the opportunity costs of remaining in school to be negatively correlated with early school leaving. This is indeed observable, however, interestingly, it is only statistically significant for young women.

The differences in the results across gender have some interesting implications. Assuming that smoking and the unemployment rate are valid indicators of the discount rate and the opportunity cost of studying respectively, the results suggest that young women are more rational (in an economic sense) and far-sighted in their choices than young men. The positive association between smoking and dropping out for young men suggests that they attribute less importance to the future (have a higher discount rate) then do young women, whereas the lack of importance of the unemployment rate, suggests that they are less rational in calculating the opportunity costs of studying. Moreover, the negative association between reading often and early school leaving for young men suggests that they attribute more importance to the consumption benefits (i.e. lower direct costs) of studying than the opportunity costs of remaining in school. 


\subsection{Testing for endogeneity}

An obvious potential problem in terms of identifying the causal effect of obesity on early school leaving concerns the possible endogeneity of obesity. As noted above, however, we feel that on a priori grounds endogeneity is unlikely to be a serious problem in the current context. Amongst other things: the well established and strong link between obesity and family background; the immediacy of the negative consequences of obesity compared to the much longer run negative consequences of early school leaving arising from reduced returns to education; and, the fact that one does not become obese overnight, it takes time to develop, all tend to support the idea that the direction of causation is from obesity to school-leaving and not the other way around. However, this type of reasoning is not sufficiently strong to exclude the possibility of endogeneity. As a first step, to attempt to control for endogeneity arising from the joint determination of obesity and school dropout, we estimated a quasi-reduced form model employing the same (and numerous) explanatory variables in both equations with the intention of reducing the likelihood of correlation between obesity and the unobserved component of the school leaving equation. Second, in table 5 we report the results of a series of two types of exogeneity test: i) using the score test proposed by Smith and Blundell (1986) for probit and tobit models; and ii) using the test suggested by Monfardini and Radice, 2008) based on the bivariate probit model. The latter involves estimating a bivariate probit model with a reduced form equation for the determination of obesity and a 'structural' equation for the determinants of early school leaving. The degree of statistical significance of the estimated correlation between error terms in the two equations constitutes the test. These two types of test employing different instruments were used because:

- any test of endogeneity relying on instruments is likely to be sensitive to the specific instruments chosen; and,

- the choice of instruments is not at all obvious in our context - the usual instruments employed - obesity amongst relatives for example - are not available and it is not obvious which other variables might be correlated with obesity but not with school leaving apart from through their influence on body mass.

\section{(Table 5 about here)}

The results support the notion that obesity is exogenous to early school leaving in the current context. The tests are never statistically significant at a $10 \%$ significance level. Thus, formal tests add support to our a priori reasoning that exogeneity appears not to be a serious problem in the results presented here. We might add that this is in line with the findings of, for example, Kenkel et al. (2006) who do not find support for the notion that high school (or GED) completion affects 
obesity. Moreover, the recent study by Sabia (2007) on the effect of obesity on scholastic performance, finds that OLS, Lewbel IV and fixed effects models all provide similar estimates of the effects of obesity on academic performance. Although, in the absence of more convincing instruments, we cannot conclude definitively that obesity is exogenous to early school leaving, the evidence presented in table 5 as well as the aforementioned results of Kenkel et al. and Sabia all support such a conclusion.

\section{Concluding comments}

In this paper we have examined the causes of obesity and, above-all its consequences in terms of its effects on early school leaving. We looked at the role of various factors, such as family background, previous educational attainment, lifestyle and local context in determining obesity and we found, in particular, that being involved in sports and/or not being involved with a partner are important determinants of the phenomenon for both young men and young women. Living on the coast also seems to be important for young women in this regard, whereas young men seem to be more influenced by living in a two parent family.

As regards its consequences, we found a strong and robust positive effect of obesity on early school leaving. The theoretical model employed, as well as previous analyses of the consequences of obesity, tend to suggest that the effects of obesity will vary with context. In our case, we rationalise this in terms of the interaction between obesity and the discount rate, the returns to education and so on. Attempts to introduce interaction terms between obesity and other explanatory variables met with partial success. The sign of the effect conforms to our expectations - for example the estimated effect of obesity on early school leaving is smaller for young people (and particularly young women) attending less academic educational institutions where the expected returns to education are lower. For young women at least, the overall effect of obesity is statistically significant even with the inclusion of interaction terms, but the estimated differential effect by school type (and other contextual variables) is not. That is, we are not able to identify with any precision differences in the effects of obesity arising in different contexts.

We also considered the possible endogeneity of obesity. As noted above, logically, obesity may cause poor scholastic performance or vice versa. Alternatively some other factor(s) may determine both obesity and early school leaving. If either of the latter situations prevail, obesity will be endogenous in the estimation of school leaving. Both a priori reasoning and more formal statistical tests of exogeneity support the idea that the effect of obesity on early school leaving is causal. However, the imperfect instruments available to us, do not allow us to make a definitive judgement on this issue. One might also add that the necessary reliance on self-reported height and 
weight to identify obese adolescents is not ideal. However, such evidence as is available, comparing self-reports with measured height and weight, suggest that under-reporting is clearly related to gender and may be related inversely to educational level amongst pre-adolescents. We were able to control for the former effect by estimating separate models for males and females. We illustrated above that any remaining bias in the estimation of the effect of obesity on early school leaving, whether related to education or not, will certainly be negative. That is, will lead to an underestimate of the effect of obesity on school leaving. Consequently, the finding of a positive and statistically relation between obesity and early school leaving cannot be the result of a spurious correlation due to misreported height and weight.

We analysed the situation of young men and young women separately which indeed proved fruitful inasmuch as there are significant differences in the causes and consequences of obesity across the sexes even at this early age. Taken as a whole, the findings suggest that obese young women suffer more serious consequences, and are more aware of them, than are obese young men. The positive association between smoking and early school leaving, and, the lack of importance of the unemployment rate found for young men, suggest that they have a higher discount rate and are less rational in calculating the opportunity costs of studying than young females. Moreover, the negative association between reading often and early school leaving for young men suggests that they attribute more importance to the consumption benefits (i.e. lower direct costs) of studying than the indirect opportunity costs. One possible explanation of these gender differences could be the earlier maturity of young women. It would certainly be worthwhile investigating this further in future research.

The findings presented here have significant implications for policies aimed at reducing obesity and/or early school leaving. First, evidence on the positive causal link running from obesity to early school leaving suggests that action aimed at reducing obesity, such as policies to encourage sport in school, may also have beneficial effects in terms of reducing early school leaving rates. The inverse relation between family permanent income and/or family educational level and early school leaving point towards the provision of financial incentives to remain in school. In this regard, one might observe that measures in this direction have recently been introduced in Italy. A number of items which may contribute to the costs of education, such as season tickets for public transport and school registration fees have recently been made tax deductable. The findings concerning the differences between adolescent boys and girls suggest policies, particularly for boys, aimed at making the longer run benefits of education more evident to them. Finally, although not statistically significant, there is some support for the idea that contextual factors - such as the type of school attended - are important in determining the effects of obesity on early school leaving. Given the 
aforementioned limitations of the analysis presented here, together with the strong relation identified between obesity and early school leaving, we would hope that this paper might above-all serve as a stimulus for further work investigating this link. 
Aknowledgements: The paper has benefited greatly from the comments provided by the journal's anonymous referees as well as from discussions with Marcello D'Amato, Giuseppe Russo and Luigi Senatore. Usual disclaimers apply.

\section{References}

Amendola, G., Mancini, P., 2005. Mens Sana in Corpore Sano: Attività fisica e aspetto fisico degli adolescenti, paper presented at the Società Italiana di Statistica, Giornate di Studio sulla Popolazione, Padova, 16-18 February.

Anderson, P.M., Butcher, K.F., Levine, P.B., 2003. Maternal employment and overweight children. Journal of Health Economics 22, 477 -504.

Averett, S., Korenman, S., 1996. The economic reality of 'The beauty myth. Journal of Human Resources 31(2), 304-330.

Averett, S., Korenman, S., 1999. Black-white differences in social and economic consequences of obesity. International Journal of Obesity 23, $166-173$.

Barro, R.J., 1996. Health, Human Capital and Economic Growth. Pan American Health Organisation, Washington D.C..

Barron, J., Ewing, B., Waddell, G., 2000. The effects of high school athletic participation on education and labor market outcomes. The Review of Economics and Statistics 82 (3), 409 421.

Baum II, C.L., Ruhm, C., 2007. Age, socio-economic status and obesity growth. NBER Working Paper no. 13289.

Becker, G.S., 1964. Human capital, a theoretical and empirical analysis with special reference to education. Chicago University Press, Chicago.

Brandolini, A., Cannari, L., D’Alessio, G.D. and Faiella, I., 2004. Household wealth distribution in Italy in the 1990s, Tema di discussione del Servizio Studi no. 530, Banca d'Italia, Roma.

Brunello, G., D’Hombres, B., 2007. Does body weight affect wages? Evidence from Europe. Economics and Human Biology 5, 1 - 19.

Burkhauser, R.V., Cawley, J., 2008. Beyond BMI: The value of more accurate measures of fatness and obesity in social science research. Journal of Health Economics 27 (2), 519 - 529.

Burke, M.A., Frank, H., 2006. Social dynamics of obesity. Federal Reserve Bank of Boston, Public policy Discussion paper n. 06-5.

Cawley, J., 2000. Body weight and women's labor market outcomes. NBER Working paper no. 7841.

Cawley, J., 2004. The impact of obesity on wages. Journal of Human Resources 39 (2), 451- 474.

Cawley, J., Liu, F., 2007. Maternal employment and childhood obesity: a search for mechanisms in time use data. NBER Working paper no. 13600. 
Cawley, J., Spiess, C.K., 2008. Obesity and skill attainment in early childhood. Economics and Human Biology 6, 388 -397.

Chou, S.Y., Grossman M., Saffer, H., 2004. An economic analysis of adult obesity: results from the behavioral risk factor surveillance system. Journal of Health Economics 23, 565-587.

Cole, T.J., Bellizzi, M.C., Flegal, K.M., Dietz, W.H., 2000. Establishing a standard definition for child overweight and obesity worldwide: international survey. British Medical Journal 320, $1240-45$.

Conley, D., Glauber, R., 2005. Gender, body mass and economic status. NBER Working paper no. 11343.

Costa- Font, J., Gil, J. 2005. Obesity and the incidence of chronic diseases in Spain: a seemingly unrelated probit approach. Economics and Human Biology 3, 188-214.

Crosnoe, R., Muller, C., 2004. Body mass index, academic achievement, and school context: examining the educational experiences of adolescent at risk of obesity. Journal of Health and Social Behaviour 45, 393 - 407.

Crosnoe, R., 2007. Gender, obesity and education. Sociology of education 80 (3), 241- 260.

Cutler, D.M., Glaeser, E.L., Shapiro, J.M., 2003. Why have Americans become more obese?. Journal of Economic Perspectives 17, 93-118.

Danubio, M.E., Miranda, G., Vinciguerra, M.G., Vecchi, E., Rufo, F., 2008. Comparison of selfreported and measured height and weight: Implications for obesity research among young adults. Economics and Human Biology 6, 181-190.

Datar, A., Sturm, R., Magnabosco, J.L., 2004. Childhood overweight and academic performance: National study of kindergartners and first-graders. Obesity Research 12 (1), $58-68$.

Ewing, R., Schmid, T., Killingsworth, R., Zlot, A., Raudenbush, S., 2003. Relationship between urban sprawl and physical activity, obesity and morbidity. American Journal of Health Promotion 18 (1), 47-57.

Fabbri, D., Monfardini, C., Radice, R., 2004. Testing exogeneity in the bivariate probit model: Monte Carlo evidence and an application to health economics. Working Paper No. 514. Dipartimento di Scienze Economiche, Università di Bologna.

Fersterer, J., Winter-Ebmer, R., 2003. Smoking, discount rates, and returns to education. Economics of Education Review 22, 561 - 566.

Fuchs, V., 1982. Time preference and health: an exploratory study. in Fuchs, V.,(ed.), Economic Aspects of Health, University of Chicago Press, Chicago, pp. 93-120.

Fuchs, V., 2004. Reflections on the socio-economic correlates of health. Journal of Health Economics 23, $653-661$. 
Gable, S., Lutz, S., 2000. Household, parent, and child contributions to childhood obesity. Family Relations 49, 293-300.

Gargiulo, L., Gianicolo, E., Brescianini, S., 2004. Eccesso di peso nell'infanzia e nell'adolescenza. in Atti del Convegno ISTAT: Informazione statistica e politiche per la promozione della salute, Roma, 10 -12 Settembre 2002.

Gianicolo, E., 2003. Analisi della validità dell'indice di massa corporea nella popolazione italiana. Rivista di Statistica Ufficiale 3, 41-63.

Greenwood, D. T., 1987. Age, income, and household size: their relation to wealth distribution in the U.S., in International Comparisons of the Distribution of Household Wealth, edited by Wolff, E. N. Oxford University Press, Oxford.

Grossman, M., 1972. On the concept of health capital and the demand for health. Journal of Political Economy 80 (2), 223-255.

Grossman, M., 2000. The human capital model. in Newhouse, J.P., Culyer, A., (eds.) - Handbook of Health Economics, vol.1, 347 - 408, Elsevier Science B.V..

Grossman, M., 2004. The demand for health, 30 years later: a very personal retrospective and prospective reflection. Journal of Health Economics 23, 629-636.

Hanushek, E.A., 1986. The economics of schooling: production and efficiency in public schools. Journal of Economic Literature, 24, 1141-1177.

Harper, B., 2000. Beauty, stature and the labor market: a british cohort study. Oxford Bulletin of Economics and Statistics 62, special issue, $771-800$.

Kaestner, R., Grossman, M., 2008. Effects of weight on children's educational achievement. NBER Working paper no. 13764.

Karnehed, N., Rasmussen, F., Hemmingsson, T., Tyneliu, P., 2006. Obesity and attained education: cohort study of more than 700,000 Swedish men. Obesity 14, 1421-1428.

Kenkel, D., Lillard, D., Mathios, A., 2006. The roles of high school completion and GED receipt in smoking and obesity. Journal of Labor Economics 24 (3), 635-660.

Komlos, J., Smith, P., Bogin, B., 2004. Obesity and the rate of preference: is there a connection? Journal of Biosocial Science 36, $209-219$.

IOTF 2005. EU Platform briefing paper. EU Platform on Diet, Physical Activity and Health, Brussels, March 15.

Istat 2002. Indagine multiscopo su condizioni di salute e ricorso ai servizi sanitari 1999-2000, Istat, Roma.

Istat 1997. I sistemi locali del lavoro 1991. Istat, Roma.

Jansen,W., van de Looij-Jansen, P.M., Ferreira, I., deWilde, E.J., 2006. Differences in measured and self-reported height and weight in Dutch adolescents. Ann. Nutr. Metab. 50, 339-346. 
Lakdawalla, D., Philipson, T., 2002. The growth of obesity and technological change: a theoretical and empirical examination. NBER Working paper n. 8946.

Lakdawalla, D., Philipson T., Bhattacharya, J., 2005. Welfare-enhancing technological change and the growth of obesity. American Economic Review 95 (2), 253-257.

Lake, J. K., Power, C., Cole, T.J., 1997. Child to adult body mass index in the 1958 british birth cohort: associations with parental obesity. Archives of Desease in Childhood 77, 376-381.

La Torre, G., Masala, D., De Vito, E., Langiano, E., Capelli, G., Ricciardi, W., PHASES (Physical activity and socio-economic status) collaborative group, 2006. Extra-curricular physical activity and socio-economic status in Italian adolescents. BMC Public Health, 6: 22.

Lempert, D., 2007. Women's increasing wage penalties from being overweight and obese. U.S. Bureau of Labor Statistics Working paper no. 414.

Lissau, I., Overpeck, M.D., Ruan, W.J., Due, P., Holstein, B.E., Hediger, M.L., 2004. Body mass index and overweight in adolescents in 13 European countries, Israel, and the United States. Archives of Paediatrics and Adolescent Medicine 158 (1), 27-33.

Lobstein, T., Baur, L., Uauy, R., 2004. Obesity in children and young people: a crisis in public health. Obesity Reviews 5 (suppl. 1), 4-85.

Lobstein, T., Frelut, M. L., 2003. Prevalence of overweight among children in Europe. Obesity Reviews 4, 195-200.

Long, J., Caudill, S., 1991. The impact of participation in intercollegiate athletics on income and graduation. Review of Economics and Statistics 73, 525 -531.

Ministero della Pubblica Istruzione, 2008. La Dispersione scolastica: Indicatori di base anno scolastico 2006/07, Direzione Generale Studi e Programmazione, Ufficio di Statistica, Roma.

Mokdad, A., Bowman, B., Ford, E., Vinicor, F., Marks, J., Koplan, J., 2001. The continuing epidemic of obesity and diabetes in the United States. JAMA 286, 1195-1200.

Monfardini, C., Radice, D., Testing exogeneity in the bivariate probit model: a Monte Carlo study. Oxford Bulletin of Economics and Statistics 70, 271-282.

Morris, S., 2006. Body mass index and occupational attainment. Journal of Health Economics 25, 347-364.

O’Donoghue, T.O., Rabin, M., 1999. Doing it now or later. American Economic Review 89, 103 124.

O'Donoghue, T.O., Rabin, M., 2000. The economics of immediate gratification. Journal of Behavioural Decision Making 13, 233-250.

O’Higgins, N., 1994. YTS, employment and sample selection bias. Oxford Economic Papers 46 (4), 605-628. 
O'Higgins, N., D'Amato, M., Caroleo, F.E., Barone, A., 2007. Gone for Good? Determinants of school dropout in Southern Italy. Giornale degli Economisti 66 (2), 207 - 245.

Pagan, J.A., Davila, A., 1997. Obesity, occupational attainment, and earnings. Social Science Quarterly 78 (3), 756-770.

Pfeifer, C., Cornelißen, T., 2007. The impact of participation in Sports on Educational Attainment: new Evidence from Germany. IZA Discussion paper no. 3160.

Philipson, T.J., Posner, R., 1999. The long-run growth in obesity as a function of technological change. NBER working paper no. 7423.

Philipson, T. J., 2001. The world-wide growth in obesity: an economic research agenda. Health Economics 10, $1-7$.

Rashad, I., 2006. Structural estimation of caloric intake, exercise, smoking, and obesity. The Quarterly Review of Economics and Finance 46, 268 - 283.

Rashad, I., Grossman, M., Chou, S.Y., 2005. The super size of America : an economic estimation of body mass index and obesity in adults. NBER Working paper no. 11584.

Rashad, I., Markowitz, S., 2007. Incentives in obesity and health insurance. NBER Working paper no. 13113.

Register, C.A., Williams, D.R., 1990. Wage effects of obesity among young workers. Social Science Quarterly 71 (1), 130 - 141.

Rosin, O., 2008. The economic causes of obesity: a survey. Journal of Economic Surveys 22 (4), 617-647.

Ruhm, C.J., 2000. Are recessions good for your health?. Quarterly Journal of Economics 115, 616 650.

Sabia, J.J., 2007. The effect of body weight on adolescent academic performance. Southern Economic Journal 74, 871-900.

Sarlio-Lähteenkorva, S., Lahelama, E., 1999. The association of body mass index with social and economic disadvantage in women and men. International Journal of Epidemiology 28, 445449.

Sanz de Galdeano, A., 2005. The obesity epidemic in Europe. IZA Discussion paper no. 1814.

Sargent, J.D., Blanchflower, D.G., 1994. Obesity and stature in adolescence and earnings in young adulthood. Archives of paediatric adolescent medicine 148, $681-68$.

Schroeter, C., Lusk, J., Tyner, W., 2008. Determining the impact of food price and income changes on body weight. Journal of Health economics 27, 45-68.

Smith, P.K., Bogin, B., Bishai, D., 2005. Are time preference and body mass index associated? Evidence from the National Longitudinal Survey of Youth. Economics and Human Biology $3,259-270$. 
Smith, R.J, Blundell, R.W., 1986. An exogeneity test for a simultaneous equation Tobit model with an application to labor supply. Econometrica 54, 679-686.

Suhrcke, M., McKee, M., Sauto Arce, R., Tsolova, S., Mortensen, J., 2005. The contribution of health to the economy in the EU, European Commission, 2005.

Taras, H., Potts-Datema, W., 2005. Obesity and student performance at school. Journal of School Health 75 (8), $291-295$.

Tosini, N., 2008. The socioeconomic determinants and consequences of women's body mass. Mimeo, University of Pennsylvania.

Viner, R.M., Cole, T.J., 2005. Adult socioeconomic, educational, social and psychological outcomes of childhood obesity: a national birth cohort study. British Medical Journal 330, 1354-1360.

Wang, Y., Lobstein, T. 2006. Worldwide trends in childhood overweight and obesity. International Journal of Paediatric Obesity 1, 11-25.

Wendt, M. And Kinsey, J., 2009. Childhood overweight and school outcomes. Paper presented at the Agricultural and Applied Economics Association Annual Meeting, Milwaukee.

WHO Regional Office for Europe, 2006a. Addressing the socioeconomic determinants of healthy eating habits and physical activity levels among adolescents. WHO, Geneva.

WHO Regional Office for Europe, 2006b. The challenge of obesity in the WHO European Region and the strategies for response. WHO, Geneva.

Zhang, L., Rashad, I., 2008. Obesity and time preference: the health consequences of discounting the future. Journal of Biosocial Science 40, $97-113$. 
Table 1:Overweight (including obesity) and Early School-Leaving by Macro-Region for Adolescents (aged 14-17) in Italy.

\begin{tabular}{|c|c|c|c|c|}
\hline & \multicolumn{3}{|c|}{$\begin{array}{l}\text { Obese adolescents as a \% of all adolescents } \\
\text { aged 14-17. }\end{array}$} & \multirow{2}{*}{$\begin{array}{c}\text { Secondary School leavers } \\
(14-17) \text { as a \% of 14-17 } \\
\text { year old enrolled } \\
\text { Secondary School } \\
\text { students } \\
\text { Males \& Females } \\
\end{array}$} \\
\hline & Males & Females & Males \& Females & \\
\hline North-East & \multirow{2}{*}{14.0} & \multirow{2}{*}{11.4} & \multirow{2}{*}{12.7} & 1.3 \\
\hline North-West & & & & 1.1 \\
\hline Centre & 17.3 & 8.4 & 12.8 & 1.4 \\
\hline South & \multirow{2}{*}{21.8} & \multirow{2}{*}{11.2} & \multirow{2}{*}{16.6} & 1.9 \\
\hline $\begin{array}{l}\text { Islands } \\
\text { (Sardinia \& } \\
\text { Sicily) }\end{array}$ & & & & 2.7 \\
\hline Italy & 18.2 & 10.8 & 14.5 & 1.6 \\
\hline
\end{tabular}

Source: Overweight and obesity - Gargiulo et al (2004); Early school leavers - Ministero della Pubblica Istruzione (2008).

Notes: Data for Overweight and obesity refers to 1999-2000 and for early school leavers to 2006-7. More recent data for adolescent obesity is not available. 
1. Early school leaver

2. Obese

3. Live in owner occupied home

4. No. of household members (in natural log.s)

5. No. of domestic appliances (in natural log.s)

6. Both parents working

7. Both parents live in household

8. Mother has lower secondary education

9. Mother has upper secondary or tertiary education

10. Individual is the first born in the family

11. Parents often read to individual when as a child

12. Parents helped often with homework

13. Individual has permanent health problems

14. Individual failed a year during middle school

15. Individual failed a year during secondary school

16. Individual often skips school

17. Individual attends a 'Liceo' school

18. Individual travels to school on foot

19. Individual travels to school by bus

20. Individual smokes

21. Individual often looks after children

22. Individual often does gardening

23. Individual often does sport

24. Individual often goes to the cinema

25. Individual often reads books

27. Individual never spends time with partner

28. Individual lives in Salerno (City)

29. Individual lives on the coast

30. Local unemployment rate $(\%)$

\begin{tabular}{|c|c|c|c|}
\hline \multicolumn{2}{|c|}{ Females $(n=342)$} & \multicolumn{2}{|c|}{ Males ( $n=455)$} \\
\hline mean & $\begin{array}{c}\text { std. dev. } \\
\text { (continuous } \\
\text { variables) }\end{array}$ & mean & $\begin{array}{c}\text { std. dev. } \\
\text { (continuous } \\
\text { variables) }\end{array}$ \\
\hline 0.24 & - & 0.27 & - \\
\hline 0.07 & - & 0.15 & - \\
\hline 0.79 & - & 0.80 & - \\
\hline 1.50 & 0.25 & 1.47 & 0.24 \\
\hline 2.62 & 0.27 & 2.69 & 0.26 \\
\hline 0.33 & - & 0.35 & - \\
\hline 0.90 & - & 0.91 & - \\
\hline 0.48 & - & 0.44 & - \\
\hline 0.37 & - & 0.37 & - \\
\hline 0.36 & - & 0.40 & - \\
\hline 0.12 & - & 0.06 & - \\
\hline 0.23 & - & 0.21 & - \\
\hline 0.04 & - & 0.02 & - \\
\hline 0.03 & - & 0.07 & - \\
\hline 0.13 & - & 0.20 & - \\
\hline 0.09 & - & 0.15 & - \\
\hline 0.30 & - & 0.20 & - \\
\hline 0.30 & - & 0.22 & - \\
\hline 0.51 & - & 0.49 & - \\
\hline 0.23 & - & 0.26 & - \\
\hline 0.06 & - & - & - \\
\hline- & - & 0.01 & - \\
\hline 0.20 & - & 0.35 & - \\
\hline 0.05 & - & 0.06 & - \\
\hline 0.13 & - & 0.04 & - \\
\hline 0.48 & - & 0.44 & - \\
\hline 0.39 & - & 0.39 & - \\
\hline 0.38 & - & 0.42 & - \\
\hline 11.85 & 1.95 & 11.80 & 1.93 \\
\hline
\end{tabular}

Note: All the variables except for variable no.s 4, 5 and 30 are dichotomous. Variables 4 and 5 are integer values transformed by natural logarithms. The local unemployment rate is defined at the level of the local labour market system (SLL) as defined by ISTAT (the Italian National Statistical Agency). Further description and discussion of the variables is included in section 5 of the text. 
Table 3: Probit model of the determinants of obesity

Intercept

Live in owner occupied home

No. of household members (in natural log.s)

No. of domestic appliances (in natural log.s)

Both parents working

Both parents live in household

Mother has lower secondary education

Mother has upper secondary or tertiary

education

Individual is the first born in the family

Parents often read to individual when as a child

Parents helped often with homework

Individual has permanent health problems

Individual failed a year during middle school

Individual failed a year during secondary

school

Individual often skips school

Individual attends a 'Liceo'

Individual travels to school on foot

Individual travels to school by bus

Individual smokes

Individual often looks after children

Individual often does gardening

Individual often does sport

Individual often goes to the cinema

Individual often reads books

Individual never spends time with partner

Individual lives in Salerno (City)

Individual lives on the coast

Local unemployment rate (\%)

$\mathbf{N}$

Pseudo R-squared

\section{Obesity}

\begin{tabular}{|l|c|l|c|}
\hline \multicolumn{2}{|c|}{ Female } & \multicolumn{2}{c|}{ Male } \\
\hline Coeff. & Std Err. & Coeff. & Std Err. \\
\hline & & & \\
\hline
\end{tabular}

$-2.887$

$-0.369$

0.370

0.397

$-0.348$

$-0.253$

$-0.065$

0.175

$-0.090$

$-0.618$

$-0.154$

0.658

0.488

0.402

$-0.480$

$-0.571$

$-0.490$

$-0.469$

$-0.262$

$-0.528$

$-$

$-0.981 *$

0.290

0.536

$0.466^{*}$

0.401

$-0.705 * *$

0.062
(1.806)

(0.281)

(0.612)

(0.514)

(0.318)

(0.527)

(0.349)

0.163

$-0.034$

0.131

$-0.006$

$-0.289$

$-0.494 *$

$-0.146$

(0.416)

$-0.375$

(0.287)

0.173

(0.556)

0.011

(0.336)

0.132

(0.462)

0.342

(0.562)

$-0.116$

(0.354)

$-0.041$

(0.561)

0.002

(0.362)

$-0.414$

(0.365)

$-0.240$

(0.324)

0.004

(0.354)

0.022

(0.681)

-
$(0.593)$

$-0.483$

(0.613)

$-0.462 * *$

0.428

(0.374)

0.196

(0.269)

$0.474 * * *$

(0.298)

$-0.069$

(0.349)

0.017

(0.065)
(1.065)

(0.195)

(0.353)

(0.314)

(0.182)

(0.283)

(0.209)

(0.249)

(0.160)

(0.356)

(0.201)

(0.467)

(0.291)

(0.199)

(0.220)

(0.262)

(0.235)

(0.191)

(0.185)

(0.639)

(0.186)

(0.307)

(0.382)

(0.159)

(0.182)

(0.182)

(0.045)

Notes: Standard errors in parentheses; statistical significance indicated as follows: $* * *$ for $\mathrm{p}<0.01, * *$ for $\mathrm{p}<0.05$ and $*$ for $\mathrm{p}<0.1$ 
Table 4: Probit model of the determinants of early school leaving

\begin{tabular}{|c|c|c|c|c|c|c|c|c|}
\hline & \multicolumn{8}{|c|}{ probability of early school leaving } \\
\hline & \multicolumn{4}{|c|}{ Female } & \multicolumn{4}{|c|}{ Male } \\
\hline & \multicolumn{2}{|c|}{ No interaction } & \multicolumn{2}{|c|}{$\begin{array}{c}\text { With interaction } \\
\text { terms }\end{array}$} & \multicolumn{2}{|c|}{ No interaction } & \multicolumn{2}{|c|}{$\begin{array}{l}\text { With interaction } \\
\text { terms }\end{array}$} \\
\hline & Coeff & $\begin{array}{l}\text { Std } \\
\text { Err. }\end{array}$ & Coeff & Std Err. & Coeff & $\begin{array}{l}\text { Std } \\
\text { Err. }\end{array}$ & Coeff & $\begin{array}{l}\text { Std } \\
\text { Err. }\end{array}$ \\
\hline Intercept & $2.904 * *$ & $(1.392)$ & $2.956^{* *}$ & $(1.436)$ & 1.785 & $(1.092)$ & 1.713 & $(1.118)$ \\
\hline Obese & $0.690 *$ & $(0.367)$ & $2.110^{* *}$ & $(1.058)$ & $0.743 * * *$ & $(0.229)$ & 0.113 & $(0.770)$ \\
\hline Live in owner occupied home & 0.145 & $(0.266)$ & 0.207 & $(0.277)$ & 0.075 & $(0.216)$ & 0.009 & $(0.220)$ \\
\hline $\begin{array}{l}\text { No. of household members (in } \\
\text { natural log.s) }\end{array}$ & 0.304 & $(0.468)$ & 0.220 & $(0.489)$ & 0.420 & $(0.365)$ & 0.498 & $(0.369)$ \\
\hline $\begin{array}{l}\text { No. of domestic appliances (in } \\
\text { natural log.s) }\end{array}$ & $-0.776^{*}$ & $(0.400)$ & $-0.785 *$ & $(0.410)$ & $-0.971 * * *$ & $(0.332)$ & $-0.894 * * *$ & $(0.343)$ \\
\hline Both parents working & 0.090 & $(0.257)$ & 0.0870 & $(0.262)$ & -0.041 & $(0.197)$ & -0.038 & $(0.200)$ \\
\hline Both parents live in household & -0.282 & $(0.382)$ & -0.258 & $(0.394)$ & 0.421 & $(0.344)$ & 0.373 & $(0.347)$ \\
\hline $\begin{array}{l}\text { Mother has lower secondary } \\
\text { education }\end{array}$ & $-0.608 * *$ & $(0.270)$ & $-0.610^{* *}$ & $(0.275)$ & $-0.387 *$ & $(0.206)$ & $-0.470 * *$ & $(0.211)$ \\
\hline $\begin{array}{l}\text { Mother has upper secondary or } \\
\text { tertiary education }\end{array}$ & $-0.703 * *$ & $(0.332)$ & $-0.788 * *$ & $(0.350)$ & $-0.832 * * *$ & $(0.252)$ & $-0.876^{* * *}$ & $(0.257)$ \\
\hline $\begin{array}{l}\text { Individual is the first born in the } \\
\text { family }\end{array}$ & $-0.574 * *$ & $(0.241)$ & $-0.687 * * *$ & $(0.255)$ & $-0.350 *$ & $(0.182)$ & $-0.371 * *$ & $(0.185)$ \\
\hline $\begin{array}{l}\text { Parents often read to individual } \\
\text { when as a child }\end{array}$ & -0.217 & $(0.389)$ & -0.285 & $(0.398)$ & -0.503 & $(0.402)$ & -0.570 & $(0.417)$ \\
\hline $\begin{array}{l}\text { Parents helped often with } \\
\text { homework }\end{array}$ & -0.346 & $(0.256)$ & -0.311 & $(0.259)$ & 0.004 & $(0.231)$ & -0.018 & $(0.236)$ \\
\hline $\begin{array}{l}\text { Individual has permanent health } \\
\text { problems }\end{array}$ & 0.609 & $(0.473)$ & 0.769 & $(0.505)$ & 0.360 & $(0.555)$ & 0.464 & $(0.558)$ \\
\hline $\begin{array}{l}\text { Individual failed a year during } \\
\text { middle school }\end{array}$ & 0.719 & $(0.485)$ & $0.892 *$ & $(0.499)$ & $1.116^{* * *}$ & $(0.314)$ & $1.080 * * *$ & $(0.322)$ \\
\hline $\begin{array}{l}\text { Individual failed a year during } \\
\text { secondary school }\end{array}$ & $0.875^{* * * *}$ & $(0.294)$ & $1.000 * * *$ & $(0.311)$ & $0.892 * * *$ & $(0.199)$ & $0.835 * * *$ & $(0.212)$ \\
\hline Individual often skips school & $0.758 * *$ & $(0.317)$ & $0.779 * *$ & $(0.334)$ & $1.174 * * *$ & $(0.236)$ & $1.168 * * *$ & $(0.238)$ \\
\hline Individual attends a 'Liceo' & $-1.847 * * *$ & $(0.458)$ & $-1.738 * * *$ & $(0.466)$ & $-1.049 * * *$ & $(0.388)$ & $-1.445^{* *}$ & $(0.572)$ \\
\hline Individual travels to school on foot & 0.181 & $(0.341)$ & 0.128 & $(0.357)$ & -0.083 & $(0.249)$ & -0.100 & $(0.256)$ \\
\hline Individual travels to school by bus & -0.191 & $(0.322)$ & -0.182 & $(0.336)$ & -0.097 & $(0.209)$ & -0.069 & $(0.215)$ \\
\hline Individual smokes & -0.110 & $(0.265)$ & -0.188 & $(0.278)$ & $0.419^{* *}$ & $(0.195)$ & $0.420 * *$ & $(0.198)$ \\
\hline $\begin{array}{l}\text { Individual often looks after } \\
\text { children }\end{array}$ & 0.143 & $(0.468)$ & 0.126 & $(0.476)$ & - & - & - & - \\
\hline Individual often does gardening & - & - & - & - & 0.143 & $(0.556)$ & 0.158 & $(0.560)$ \\
\hline Individual often does sport & $-1.579 * * *$ & $(0.481)$ & $-1.554 * * *$ & $(0.493)$ & -0.240 & $(0.199)$ & -0.248 & $(0.202)$ \\
\hline Individual often goes to the cinema & 0.498 & $(0.528)$ & 0.682 & $(0.557)$ & -0.135 & $(0.375)$ & -0.204 & $(0.394)$ \\
\hline Individual often reads books & -0.095 & $(0.378)$ & -0.0924 & $(0.404)$ & $-1.284 *$ & $(0.711)$ & $-1.280^{*}$ & $(0.741)$ \\
\hline $\begin{array}{l}\text { Individual never spends time with } \\
\text { partner }\end{array}$ & 0.312 & $(0.220)$ & 0.323 & $(0.226)$ & -0.284 & $(0.180)$ & -0.272 & $(0.181)$ \\
\hline Individual lives in Salerno (City) & -0.048 & $(0.248)$ & -0.0970 & $(0.272)$ & -0.032 & $(0.196)$ & -0.195 & $(0.221)$ \\
\hline Individual lives on the coast & 0.268 & $(0.248)$ & 0.283 & $(0.267)$ & -0.083 & (0.194) & -0.057 & $(0.217)$ \\
\hline $\begin{array}{l}\text { Local unemployment rate } \\
(\%) \text { Interaction terms }\end{array}$ & $-0.112 *$ & $(0.060)$ & $-0.107^{*}$ & $(0.064)$ & -0.057 & $(0.048)$ & -0.059 & $(0.049)$ \\
\hline Obese*technical school & & & -1.169 & $(0.989)$ & & & 0.359 & $(0.788)$ \\
\hline Obese*vocational school & & & -1.719 & $(1.274)$ & & & 0.148 & $(0.848)$ \\
\hline Obese*liceo & & & - & & & & 1.216 & (1.145) \\
\hline Obese*Salerno & & & -0.441 & $(0.921)$ & & & 0.739 & $(0.489)$ \\
\hline Obese*coast & & & 0.186 & $(0.969)$ & & & -0.146 & $(0.473)$ \\
\hline Obese*failed a year & & & -0.707 & (1.018) & & & 0.309 & $(0.469)$ \\
\hline $\begin{array}{l}\mathrm{N} \\
\text { Pseudo R-squared }\end{array}$ & & & & $\begin{array}{l}337 \\
.46\end{array}$ & 0 . & & & \\
\hline
\end{tabular}

Note: Standard errors in parentheses; statistical significance indicated as follows: $* * *$ for $\mathrm{p}<0.01, * *$ for $\mathrm{p}<0.05$ and $*$ for $\mathrm{p}<0.1$. 
Table 5: Smith-Blundell and Bivariate Probit tests of Exogeneity (p-values)

\begin{tabular}{|c|c|c|c|c|c|c|c|c|}
\hline & \multicolumn{4}{|c|}{ Females } & \multicolumn{4}{|c|}{ Males } \\
\hline & \multicolumn{2}{|c|}{ Smith-Blundell } & \multicolumn{2}{|c|}{ Bivariate Probit } & \multicolumn{2}{|c|}{ Smith-Blundell } & \multicolumn{2}{|c|}{ Bivariate Probit } \\
\hline & Separate & Cumulative & Separate & Cumulative & Separate & Cumulative & Separate & Cumulative \\
\hline $\begin{array}{l}\text { - Travel to } \\
\text { school on } \\
\text { foot, \& } \\
\text { - Travel to } \\
\text { school by bus }\end{array}$ & .75 & .75 & .75 & .75 & .99 & .99 & .95 & .95 \\
\hline $\begin{array}{l}\text { - Never } \\
\text { spend time } \\
\text { with partner }\end{array}$ & .16 & .25 & .66 & .72 & .11 & .15 & .99 & .90 \\
\hline - Salerno & .85 & .43 & .79 & .79 & .87 & .16 & .94 & .94 \\
\hline $\begin{array}{l}\text { - Often look } \\
\text { after children }\end{array}$ & .76 & .53 & .77 & .87 & - & - & - & - \\
\hline $\begin{array}{l}\text { - Often do } \\
\text { gardening }\end{array}$ & - & - & - & - & .80 & .16 & .89 & .92 \\
\hline $\begin{array}{l}\text { - Both } \\
\text { parents } \\
\text { working, \& } \\
\text { - Both } \\
\text { parents live } \\
\text { in HH }\end{array}$ & .88 & .21 & .82 & .92 & .70 & .11 & .98 & .91 \\
\hline
\end{tabular}

Note: The table reports probability values for Smith-Blundell (Smith and Blundell, 1986) and bivariate probit (Monfardini and Radice, 2008) exogeneity tests using a variety of different instruments both separately and cumulatively. In the cumulative test, variables are added to the list of instruments in the order in which they appear in the first column. Thus for example, looking at the row labelled 'Salerno', the second column indicates that a Smith-Blundell test for exogeneity using just the dummy variable 'Salerno' as an instrument in the probit model for females produces a p-value of .85, the third column indicates that an analogous test using 'Travel to school on foot', 'Travel to school by bus', 'Never spend time with partner' and 'Salerno' as instruments gives a probability value of .43. The ordering of the variables was determined by a priori judgements on their likely validity as instruments, however, in practice the ordering makes no difference to the overall result. Specifically, the exogeneity test is never statistically significant even at a $10 \%$ significance level. 
Appendix: Univariate probit models of the determinants of obesity and early school leaving out with a reduced set of explanatory variables

\begin{tabular}{|c|c|c|c|c|c|c|c|c|}
\hline \multirow[b]{4}{*}{ Intercept } & \multicolumn{4}{|c|}{ Obesity } & \multicolumn{4}{|c|}{ Early School Leaving } \\
\hline & \multicolumn{2}{|c|}{ Females } & \multicolumn{2}{|c|}{ Males } & \multicolumn{2}{|c|}{ Females } & \multicolumn{2}{|c|}{ Males } \\
\hline & Coeff. & Std Err. & Coeff. & Std Err. & Coeff. & Std Err. & Coeff. & Std Err. \\
\hline & -1.964 & $(1.546)$ & 0.492 & $(0.958)$ & $4.041 * * *$ & $(1.282)$ & 1.830 & $(1.002)$ \\
\hline Obese & - & - & - & - & $0.775 * *$ & $(0.347)$ & $0.613 * * *$ & $(0.199)$ \\
\hline Live in owner occupied home & $-0.453 *$ & $(0.254)$ & -0.004 & $(0.186)$ & 0.081 & $(0.235)$ & 0.014 & $(0.194)$ \\
\hline No. of household members (in natural log.s) & 0.230 & $(0.504)$ & 0.183 & $(0.335)$ & 0.266 & $(0.433)$ & 0.487 & $(0.348)$ \\
\hline No. of domestic appliances (in natural log.s) & 0.084 & $(0.435)$ & -0.204 & $(0.291)$ & $-1.196 * * *$ & $(0.360)$ & $-0.961 * * *$ & $(0.299)$ \\
\hline Both parents working & -0.455 & $(0.290)$ & -0.240 & $(0.171)$ & 0.013 & $(0.234)$ & -0.050 & $(0.178)$ \\
\hline Both parents live in household & -0.033 & $(0.422)$ & $-0.447 *$ & $(0.268)$ & -0.382 & $(0.313)$ & 0.350 & $(0.313)$ \\
\hline Mother has lower secondary education & -0.106 & $(0.312)$ & -0.143 & $(0.195)$ & $-0.556 * *$ & $(0.250)$ & $-0.334 *$ & $(0.192)$ \\
\hline Mother has upper secondary or tertiary education & 0.003 & $(0.356)$ & -0.450 & $(0.225)$ & $-0.609 * *$ & $(0.307)$ & $-0.747 * * *$ & $(0.235)$ \\
\hline Individual is the first born in the family & -0.191 & $(0.253)$ & 0.135 & $(0.152)$ & $-0.605^{* * *}$ & $(0.218)$ & $-0.279 *$ & $(0.164)$ \\
\hline Parents often read to individual when as a child & -0.577 & $(0.468)$ & 0.022 & $(0.322)$ & -0.379 & $(0.349)$ & $-0.742 *$ & $(0.396)$ \\
\hline Parents helped often with homework & -0.071 & $(0.299)$ & 0.136 & $(0.191)$ & -0.253 & $(0.238)$ & -0.099 & $(0.206)$ \\
\hline Individual failed a year during middle school & - & - & - & - & $0.849 *$ & $(0.464)$ & $1.305 * * *$ & $(0.292)$ \\
\hline Individual failed a year during secondary school & - & - & - & - & $0.730 * * *$ & $(0.252)$ & $1.031 * * *$ & $(0.177)$ \\
\hline Individual attends/attended a 'Liceo' & - & - & - & - & $-1.643 * * *$ & $(0.423)$ & $-0.988 * * *$ & $(0.348)$ \\
\hline Individual lives in Salerno (City) & 0.364 & $(0.260)$ & -0.088 & $(0.176)$ & -0.130 & $(0.225)$ & 0.059 & $(0.179)$ \\
\hline Individual lives on the coast & $-0.592 * *$ & $(0.299)$ & 0.018 & $(0.172)$ & 0.158 & $(0.225)$ & -0.082 & $(0.174)$ \\
\hline Local unemployment rate & 0.049 & $(0.058)$ & -0.053 & $(0.041)$ & -0.090 & $(0.055)$ & $-0.066^{*}$ & $(0.043)$ \\
\hline $\mathrm{N}$ & \multicolumn{2}{|c|}{341} & \multicolumn{2}{|c|}{455} & \multicolumn{2}{|c|}{341} & \multicolumn{2}{|c|}{455} \\
\hline Pseudo R-Squared & \multicolumn{2}{|c|}{0.09} & \multicolumn{2}{|c|}{0.05} & \multicolumn{2}{|c|}{0.37} & \multicolumn{2}{|c|}{0.33} \\
\hline
\end{tabular}

Note: Standard errors in parentheses; statistical significance indicated as follows: $* * *$ for $\mathrm{p}<0.01$, ** for $\mathrm{p}<0.05$ and $*$ for $\mathrm{p}<0.1$. 